\title{
Detection of subclinical atherosclerosis and diastolic dysfunction in patients with schizophrenia
}

This article was published in the following Dove Press journal:

Neuropsychiatric Disease and Treatment

7 October 2013

Number of times this article has been viewed

\author{
Cüneyt Ünsal' \\ Mustafa Oran ${ }^{2}$ \\ Hande Oktay Tureli ${ }^{3}$ \\ Seref Alpsoy ${ }^{4}$ \\ Sema Yeșilyurt ${ }^{5}$ \\ Mehtap Arslan ${ }^{6}$ \\ Birol Topcu ${ }^{7}$ \\ Osman Karakaya ${ }^{8}$ \\ Erhan Kurt ${ }^{6}$ \\ 'Department of Psychiatry, Namık \\ Kemal University, School of Medicine, \\ Tekirdag, Turkey; ${ }^{2}$ Department of \\ Internal Medicine, Namık Kemal \\ University, School of Medicine, \\ Tekirdag, Turkey; ${ }^{3}$ Department of \\ Cardiology, Bakırkoy Dr Sadi Konuk \\ Education and Research Hospital, \\ Istanbul, Turkey; ${ }^{4}$ Department of \\ Cardiology, Namık Kemal University, \\ School of Medicine, Tekirdag, Turkey; \\ ${ }^{5}$ Department of Psychiatry, Bağcılar \\ Training and Research Hospital, \\ Istanbul, Turkey; ${ }^{6}$ Department of \\ Psychiatry, Bakirkoy Training and \\ Research Hospital for Psychiatry \\ Neurology and Neurosurgery, \\ Istanbul, Turkey; ${ }^{7}$ Department of \\ Biostatistics, Namık Kemal University, \\ School of Medicine, Tekirdag, Turkey; \\ ${ }^{8}$ Department of Social Service, Yalova \\ University, Faculty of Economics and \\ Administrative Sciences, Yalova, Turkey
}

Correspondence: Cüneyt Ünsal Department of Psychiatry, School of Medicine, Namik Kemal University, Tekirdag 59100, Turkey

$\mathrm{Tel}+902822505 \mathrm{I} 58$

$\mathrm{Fax}+902822509950$

Email drcunsal@gmail.com
Background: Patients with schizophrenia have a higher risk for cardiovascular diseases, which is associated with early mortality compared with the nonschizophrenic population. Early diagnosis of cardiovascular diseases in asymptomatic periods in patients with schizophrenia would enhance their quality of life and reduce mortality. Echocardiography, carotid ultrasonography, and ankle brachial index (ABI) measurement are known to be beneficial methods of detecting subclinical cardiovascular diseases and of risk stratification. The present study investigated carotid intima media thickness (CIMT) and ABI and echocardiographic parameters measured via conventional and tissue Doppler echocardiography in patients with schizophrenia in comparison with a control group.

Methods: The present case-control study included 116 patients with schizophrenia and 88 healthy patients. Participants with any current comorbid psychiatric disorder, current or lifetime neurological and medical problems, current coronary artery disease, diabetes, hypertension, hypothyroidism, or hyperthyroidism or who were using antihypertensives, antidiabetic agents, or antiobesity drugs were excluded. High-resolution B-mode ultrasound images were used to measure CIMT. Conventional and tissue Doppler measurements were performed according to the recommendations of the American Society of Echocardiography.

Results: Low ABI, mitral ratio of the early (E) to late (A) ventricular filling velocities, septal $\mathrm{E}^{\prime}$, septal $\mathrm{S}^{\prime}$, lateral $\mathrm{E}^{\prime}$, lateral $\mathrm{S}^{\prime}$, septal $\mathrm{E}^{\prime} /$ septal $\mathrm{A}^{\prime}$, lateral $\mathrm{E}^{\prime} /$ lateral $\mathrm{A}^{\prime}$, and high septal $\mathrm{A}^{\prime}$, mitral E/septal $\mathrm{E}^{\prime}$, mitral E/lateral $\mathrm{E}^{\prime}$, and CIMT values were observed in the schizophrenia group compared with the control group.

Conclusion: Doppler parameters supported the hypothesis that patients with schizophrenia are at high risk for cardiovascular diseases.

Keywords: schizophrenia, carotid intima media thickness, ankle brachial index, tissue Doppler echocardiography

\section{Introduction}

Schizophrenia is a chronic, disabling psychiatric disorder with two to three times higher mortality rates than those seen in the general population. The lifetime prevalence is approximately $1 \%$ in schizophrenia patients. ${ }^{1}$ In addition to the disease's chronicity, patients with schizophrenia have a higher risk for physical diseases, including diabetes, metabolic syndrome, and cardiovascular diseases, compared with the nonschizophrenic population. Quality of life and expected survival are decreased in patients with schizophrenia because of these concomitant chronic diseases. ${ }^{2-5}$ Cardiovascular diseases, which are among the leading causes of morbidity and mortality worldwide, are more common in patients with schizophrenia; however, they usually remain underdiagnosed. ${ }^{6-8}$ Studies have shown that risk factors for cardiovascular diseases such as obesity, 
diabetes, metabolic syndrome, hypertension, dyslipidemia, smoking, and sedentary lifestyle are also more common in patients with schizophrenia than in the nonschizophrenic population. ${ }^{6,9-13}$ Treatment of comorbid physical diseases in patients with schizophrenia would enhance quality of life and reduce early deaths. Thus, providing physical health care in addition to mental health care is an important part of the treatment of patients with schizophrenia. ${ }^{4,14}$ The following measurements have been recommended for early diagnosis of comorbid physical diseases during the follow-up of patients with schizophrenia: fasting glucose, body mass index (BMI), fasting triglycerides, fasting cholesterol, waist circumference, hip circumference, high-density lipoprotein/ low-density lipoprotein ratio (HDL/LDL), blood pressure, and symptoms of diabetes. ${ }^{15}$

Carotid intima media thickness (CIMT) and the ankle brachial index (ABI) are well-studied surrogate markers of early atherosclerosis. It has been demonstrated that CIMT and $\mathrm{ABI}$ are in an independent relationship with enhanced vascular morbidity and mortality. ${ }^{16} \mathrm{ABI}$ is the ratio of the ankle brachial systolic blood pressures; values smaller than 0.90 indicate the presence of atherosclerosis. Low ABI values also serve as a predictor for cardiovascular events and mortality and help identify asymptomatic patients at risk. ${ }^{17-19}$ In recent years, CIMT has drawn interest as another predictor of cardiovascular events, and its validity as a suitable measure of atherosclerotic disease has been proven in many studies performed in different populations. ${ }^{20,21}$ Doppler echocardiography can accurately assess cardiac output, pulmonary artery pressures, and right- and left-ventricular filling pressures in patients with cardiovascular diseases. ${ }^{22}$ In many patients with cardiac disease, diastolic functions are impaired first, followed by systolic functions. Tissue Doppler echocardiography is able to detect diastolic function impairment in its early phase, even in an asymptomatic period. ${ }^{23,24}$ Because patients with schizophrenia have a high risk for cardiovascular diseases, monitoring diastolic functions via echocardiography would be beneficial for early diagnosis of cardiovascular diseases. The present study explored ABI, CIMT, and echocardiographic parameters measured via conventional and tissue Doppler echocardiography in patients with schizophrenia without previously known cardiovascular disease in comparison with a healthy control group.

\section{Materials and methods Subjects}

The present research is a case-control study. The study group was composed of 116 patients with schizophrenia, aged between 18 and 65 years (27 women and 89 men), who were recruited from the Mazhar Osman Bakırköy Education and Research Hospital Department of Psychiatry in Istanbul, Turkey. All patients had already met the criteria for schizophrenia according to the Diagnostic and Statistical Manual of Mental Disorders, Fourth Edition (DSM-IV). ${ }^{25}$ The DSM-IV criteria for schizophrenia were determined using the Turkish version of the Structured Clinical Interview for DSM-IV. ${ }^{26,27}$ All patients and healthy control participants were Turkish. Exclusion criteria were any current comorbid psychiatric disorder; current or lifetime neurological and medical problems; current coronary artery disease (CAD); diabetes; hypertension; hypothyroidism; hyperthyroidism; using antihypertensives, antidiabetic agents, or antiobesity drugs; and an inability or refusal to provide informed consent.

In addition, 88 healthy control participants ( 35 women and 53 men) who were age- and BMI-matched were included in the present study. Control patients were selected from among healthy individuals with no clinical evidence of schizophrenia and other psychiatric histories, no current medical problems, no neurologic problems, and no mental retardation. This study was carried out according to the Helsinki Declaration guidelines and was approved by the ethics committee of the Bakırköy Sadi Konuk Education and Research Hospital. Most of the patients were competent enough to provide written informed consent after a full explanation of the procedures of the study. Consent was obtained from the caretakers of patients who were not competent enough to provide written informed consent. All healthy controls accepted to participate in the study, and all of them provided written voluntary informed consent.

\section{$\mathrm{ABI}$ determination}

ABI was measured by a single observer in both groups after a 15 minute rest in a supine position. Systolic pressures of brachial arteries of both arms and systolic pressures of both ankles were measured, using a contour-wrapped $12 \mathrm{~cm}$ cuff and an $8 \mathrm{MHz}$ Doppler probe (Sonotrax 8-MHz Ultrasonic Vascular Pocket Doppler, Stork Radio, Boca Raton, FL, USA). The cuff was inflated to above the audible systolic pressure (for $20 \mathrm{~mm} \mathrm{Hg}$ ) in each artery. Then, the cuff was slowly deflated and the first audible sound by Doppler probe was recorded as systolic pressure. Six systolic artery pressures (right arm brachial artery, left arm brachial artery, right dorsalis pedis artery, left dorsalis pedis artery, right tibialis posterior artery, left tibialis posterior artery) were measured. Of the same-side dorsalis pedis and tibial posterior artery pressures, the highest one was written on the numerator as the systolic ankle pressure. The highest arm systolic pressure 
was written on the denominator, and the ratio of ankle systolic pressure to brachial artery systolic pressure was calculated. The same calculation was performed for the other ankle. The lowest ratio was accepted as the ABI.

\section{CIMT ultrasound scanning procedure}

High-resolution B-mode ultrasound images (GE Vivid I system, GE Healthcare, Milwaukee, WI, USA) (with 3.5 or $5 \mathrm{MHz}$ transducers) with a 7.0 MHz linear array transducer were used to measure CIMT. To measure CIMT, patients were placed in a supine position and asked to turn their heads to the opposite direction of the carotid artery and to keep their necks extended. Measurements were performed at a distance of $1 \mathrm{~cm}$ from the bifurcation of the internal and external carotid artery branches. CIMT was measured in the anterior, posterior, and lateral projections. The mean wall thickness of the common carotid artery was used as the key variable for statistical analysis because of its strong association with cardiovascular risk factors. CIMT was considered to be increased when it was more than $0.9 \mathrm{~mm}$, whereas arteriosclerotic plaques were considered to be present when it was $1.5 \mathrm{~mm}$ or more. ${ }^{28}$ For each variable, the mean value of measurements performed by two readers was used. The interobserver variability was evaluated on the measurements obtained from all patients.

\section{Echocardiography}

Patients were examined in the left lateral decubitus position, using a Vivid I (Vingmed Medical Systems, GE Healthcare, Milwaukee, WI, USA) phased array system equipped with conventional and tissue Doppler technology. Measurements were performed according to the recommendations of the American Society of Echocardiography. ${ }^{29}$ The ejection fraction was calculated using Simpson's method. ${ }^{30}$ The mitral inflow velocity pattern was recorded using the pulsed-wave Doppler sample volume positioned between the tips of the mitral leaflets. Three consecutive beats were measured and averaged for each parameter. From the apical 4-chamber view, peak early (E) and late (A) transmitral velocities, deceleration time, isovolumetric relaxation and contraction times, and mitral ratio of the E to A ventricular filling velocities were measured. On tissue Doppler imaging, the mitral annular septal and lateral velocities were recorded from the two- and four-chamber views. A 3-5 mm pulse-wave Doppler volume was placed, and tissue Doppler imaging signals were recorded. The Nyquist limit frequency was adjusted to $15-20 \mathrm{~cm} / \mathrm{second}$ with minimum gain and low-filter settings. Early and late diastolic velocities were obtained.
Systolic myocardial function was evaluated by measuring the peak systolic velocity.

\section{Statistical analysis}

Data were analyzed using Predictive Analytics Soft Ware statistics 18 (IBM Corporation, Armonk, NY, USA). Normality testing was performed by the KolmogorovSmirnov test. Descriptive statistics were expressed as frequency tables and cross tables for categorical variables and as a median, minimum, and maximum for numerical variables. Paired comparisons of nonnormally distributed continuous variables were performed using the Mann-Whitney $U$-test. The statistical significance level was set at $P<0.05$.

\section{Results \\ Demographic and clinical properties of participants}

One hundred sixteen patients who were diagnosed with schizophrenia and 88 healthy individuals were enrolled in the present study. The median age was 38 years in the patient group (PG) and 38.5 years in the healthy control group (HC). Median age was statistically similar in both groups. The percentage of men $(76.72 \%)$ was higher in the PG compared with the HC $(60.23 \% ; P=0.026)$. The percentage of women (23.28\%) was higher in the PG compared with the HC (39.77\%). BMI, rate of smokers, and diagnosis of diabetes mellitus or hypertension were similar between groups. The family history of CAD was more common in the HC. Thirty $(25.86 \%)$ of 116 patients with schizophrenia had a history of CAD in their first-degree relatives, and $51(57.96 \%)$ of 88 healthy controls reported a family history of CAD in their first-degree relatives $(P<0.001)$. The median values of BMI, serum glucose, serum total cholesterol, serum triglyceride, and serum LDL-cholesterol were found to be similar between groups. Serum HDL-cholesterol level was lower in the PG compared with the HC (36 mg/dL vs $42 \mathrm{mg} / \mathrm{dL}$; $P<0.001)$. The demographic and clinical characteristics of 116 patients with schizophrenia and 88 controls are presented in Table 1.

\section{Comparisons of $\mathrm{ABI}$, right CIMT, and left CIMT between groups}

The median values of ABI were, respectively, 1.07 (0.91-1.38) and 1.16(0.9-1.45) in the $\mathrm{PG}$ and the $\mathrm{HC}$, and $\mathrm{ABI}$ was significantly higher in the $\mathrm{HC}(P<0.001)$. The median value of right CIMT was $0.58 \mathrm{~mm}(0.38-1.08 \mathrm{~mm})$ in the $\mathrm{PG}$, which was significantly greater than in the $\mathrm{HC}(0.51 \mathrm{~mm} ; 0.38-0.69 \mathrm{~mm}$; $P<0.001)$. The median value of left CIMT was $0.56 \mathrm{~mm}$ 
Table I Demographic, clinic, and laboratory characteristics of schizophrenia and control groups

\begin{tabular}{|c|c|c|c|}
\hline Variable & $\begin{array}{l}\text { Schizophrenia } \\
\text { group }(n=|| 6)\end{array}$ & $\begin{array}{l}\text { Control } \\
\text { group }(n=88)\end{array}$ & $P$-value \\
\hline Age, year & $38(18-60)$ & $38.5(|8-6|)$ & NS \\
\hline \multicolumn{4}{|l|}{ Gender } \\
\hline Male & 89 (76.72) & $53(60.23)$ & 0.026 \\
\hline Female & $27(23.28)$ & $35(39.77)$ & \\
\hline $\mathrm{BMI}, \mathrm{kg} / \mathrm{m}^{2}$ & 27.99 & 29.3 & NS \\
\hline Smoker & 55.2 & 62.5 & NS \\
\hline Diabetes mellitus & $9(7.75)$ & $2(2.27)$ & NS \\
\hline Hypertension & $7(6.03)$ & $5(5.68)$ & NS \\
\hline $\begin{array}{l}\text { Family history of } \\
\text { coronary artery disease }\end{array}$ & $30(25.86)$ & 51 (57.96) & $<0.001$ \\
\hline Glucose $(\mathrm{mg} / \mathrm{dL})$ & $90(58-176)$ & $87(70-185)$ & NS \\
\hline Total cholesterol (mg/dL) & $193(108-381)$ & $194(120-303)$ & NS \\
\hline Triglyceride (mg/dL) & $164.5(38-537)$ & $160(52-481)$ & NS \\
\hline HDL cholesterol (mg/dL) & $36(22-74)$ & $42(30-7 I)$ & $<0.001$ \\
\hline LDL cholesterol (mg/dL) & $131.5(43.6-254)$ & $125(10-23 \mid)$ & NS \\
\hline
\end{tabular}

Note: Values are presented as median (minimum-maximum), number (\%), or \%, where appropriate.

Abbreviations: HDL, high-density lipoprotein; LDL, low-density lipoprotein; NS, not significant; BMI, body mass index.

$(0.48-1.17 \mathrm{~mm})$ in the $\mathrm{PG}$, which was also greater than the median value in the $\mathrm{HC}(0.51 \mathrm{~mm} ; 0.33-0.74 ; P<0.001)$. $\mathrm{ABI}$ and CIMT values of the study groups were presented in Table 2.

\section{$M$ mode and pulsed-Doppler findings in the PG and HC}

The median values of diastolic diameter, systolic diameter, interventricular septum, posterior wall, ejection fraction, mitral E, deceleration time, isovolumetric relaxation time, isovolumetric contraction time, and ejection time were found to be similar between groups. The median A peak value was $74 \mathrm{~cm} /$ second $(40-124 \mathrm{~cm} / \mathrm{s})$ in the $P G$, which was significantly higher than in the HC $(64 \mathrm{~cm} / \mathrm{s} ; 33-101 \mathrm{~cm} / \mathrm{s}$; $P=0.003)$. The median value of diameter of left atrium was longer in the PG compared with the $\mathrm{HC}$ (median values of diameters of left atrium of the $\mathrm{PG}$ and the $\mathrm{HC}$, respectively: $34 \mathrm{~mm}[25-45 \mathrm{~mm}]$ and $30 \mathrm{~mm}[23-37 \mathrm{~mm}] ; P<0.001)$. The E/A ratio was significantly lower in the $\mathrm{PG}$, at 1.15 (0.58-2.12) compared with in the HC (1.40; 0.76-2.12;

Table $2 \mathrm{ABI}$ and CIMT in the schizophrenia and control groups

\begin{tabular}{llll}
\hline Variable & $\begin{array}{l}\text { Schizophrenia } \\
\text { group }(\mathbf{n}=1 \mathrm{I})\end{array}$ & $\begin{array}{l}\text { Control } \\
\text { group }(\mathbf{n}=\mathbf{8 8})\end{array}$ & $\boldsymbol{P}$-value \\
\hline $\mathrm{ABI}$ & $\mathrm{I} .07(0.9 \mathrm{I}-\mathrm{I} .38)$ & $\mathrm{I} .16(0.9-1.45)$ & $<0.00 \mathrm{I}$ \\
Right CIMT $(\mathrm{mm})$ & $0.58(0.38-1.08)$ & $0.5 \mathrm{I}(0.38-0.69)$ & $<0.00 \mathrm{I}$ \\
Left CIMT $(\mathrm{mm})$ & $0.56(0.48-1.17)$ & $0.5 \mathrm{I}(0.33-0.74)$ & $<0.00 \mathrm{I}$ \\
\hline
\end{tabular}

Note: Values are presented as median (minimum-maximum).

Abbreviations: $\mathrm{ABI}$, ankle brachial index; $\mathrm{CIMT}$, carotid intima media thickness.
$P<0.001)$. Conventional parameters measured via Doppler echocardiography in the schizophrenia and control groups are presented in Table 3.

\section{Tissue Doppler parameters in the PG and $\mathrm{HC}$}

The mitral annulus septal $\mathrm{A}^{\prime}$ was higher in the PG compared with the $\mathrm{HC}(P<0.001)$, whereas the mitral annulus septal $\mathrm{E}^{\prime}$, mitral annulus septal $\mathrm{S}^{\prime}$, mitral annulus lateral $\mathrm{E}^{\prime}$, and mitral annulus lateral $\mathrm{S}^{\prime}$ were lower in the $\mathrm{PG}$ (respectively, $P=0.003, P<0.001, P<0.001$, and $P=0.002)$. The mitral annulus lateral $\mathrm{A}^{\prime}$ was similar between groups. The median values of the mitral annulus septal $\mathrm{E}^{\prime} /$ mitral annulus septal $\mathrm{A}^{\prime}$ ratio and the mitral annulus lateral $\mathrm{E}^{\prime} /$ mitral annulus lateral $\mathrm{A}^{\prime}$ ratio were found to be lower in the PG $(P<0.001)$. The median value of the mitral $E / m i t r a l$ annulus septal $E^{\prime}$ and mitral $\mathrm{E} / \mathrm{mitral}$ annulus lateral $\mathrm{E}^{\prime}$ ratios were higher in the PG compared with the $\mathrm{HC}(P=0.004$ and $P<0.001$, respectively). Tissue Doppler parameters of the study groups are presented in Table 4.

\section{Discussion}

Although no statistically significant difference was found between the schizophrenia and control groups with regard to cardiovascular risk, except for family history of cardiovascular disease, patients with schizophrenia had decreased $\mathrm{ABI}$ and increased CIMT, which are markers of subclinical atherosclerosis; no statistically significant difference in

Table $3 \mathrm{M}$ mode and pulsed-Doppler indices in the schizophrenia and control groups

\begin{tabular}{|c|c|c|c|}
\hline Variable & $\begin{array}{l}\text { Schizophrenia } \\
\text { group }(n=|| 6)\end{array}$ & $\begin{array}{l}\text { Control } \\
\text { group }(n=88)\end{array}$ & $P$-value \\
\hline Diastolic diameter (mm) & $47.5(39-6 I)$ & $47(39-53)$ & NS \\
\hline Systolic diameter (mm) & 31 (24-39) & $30(23-38)$ & NS \\
\hline $\begin{array}{l}\text { Interventricular } \\
\text { septum }(\mathrm{mm})\end{array}$ & $11(8-16)$ & II (8-15) & NS \\
\hline Posterior wall (mm) & $10(7-14)$ & $10(8-14)$ & NS \\
\hline Ejection fraction (\%) & $65(55-70)$ & $66(60-74)$ & NS \\
\hline Mitral E peak (cm/s) & $81(47-157)$ & $84.5(42-125)$ & NS \\
\hline Mitral A peak (cm/s) & $74(40-124)$ & $64(33-101)$ & 0.003 \\
\hline Deceleration time (ms) & $180(100-324)$ & $172(95-286)$ & NS \\
\hline $\begin{array}{l}\text { Isovolumetric relaxation } \\
\text { time }(\mathrm{ms})\end{array}$ & $85(52-126)$ & $89(64-114)$ & NS \\
\hline $\begin{array}{l}\text { Isovolumetric contraction } \\
\text { time (ms) }\end{array}$ & $47(32-78)$ & $45(25-64)$ & NS \\
\hline Ejection time & $279(101-366)$ & $273(191-350)$ & NS \\
\hline Left atrium (mm) & $34(25-45)$ & $30(23-37)$ & $<0.001$ \\
\hline Mitral E/A ratio & $1.15(0.58-2.12)$ & $1.40(0.76-2.12)$ & $<0.001$ \\
\hline
\end{tabular}

Note: Values are presented as median (minimum-maximum).

Abbreviations: E/A ratio, ratio of the early $(E)$ to late $(A)$ ventricular filling velocities; NS, not significant. 
Table 4 Tissue Doppler parameters in the schizophrenia and control groups

\begin{tabular}{|c|c|c|c|}
\hline Variable & $\begin{array}{l}\text { Schizophrenia } \\
\text { group }(n=|| 6)\end{array}$ & $\begin{array}{l}\text { Control } \\
\text { group }(n=88)\end{array}$ & $P$-value \\
\hline Septal E' (cm/s) & $10.5(5-18)$ & $12(6-17)$ & 0.003 \\
\hline Septal $A^{\prime}(\mathrm{cm} / \mathrm{s})$ & $10(4-17)$ & $9(5-14)$ & $<0.001$ \\
\hline Septal S' (cm/s) & $8(4-16)$ & $9(7-13)$ & $<0.00$ I \\
\hline Lateral E' (cm/s) & $10.5(4-25)$ & I $3.5(7-20)$ & $<0.00$ I \\
\hline Lateral $A^{\prime}(\mathrm{cm} / \mathrm{s})$ & $10.0(6-18)$ & $9.9(5-18)$ & NS \\
\hline Lateral $\mathrm{S}^{\prime}(\mathrm{cm} / \mathrm{s})$ & $8(4-16)$ & $9(7-13)$ & 0.002 \\
\hline Septal E'/septal A' & $1.13(0.46-2.00)$ & $1.42(0.46-2.00)$ & $<0.001$ \\
\hline E peak/septal E' & $7.94(3.59-26.20)$ & $6.92(4.67-13.29)$ & 0.004 \\
\hline Lateral $E^{\prime}$ /lateral $A^{\prime}$ & $1.05(0.4 I-3.29)$ & $1.67(0.53-3.20)$ & $<0.00 \mathrm{I}$ \\
\hline E peak/lateral E' & 7.71 (3.44-17.44) & $6.19(3.85-9.57)$ & $<0.001$ \\
\hline
\end{tabular}

Note: Values are presented as median (minimum-maximum).

Abbreviations: $A$, late ventricular filling velocity; $E$, early ventricular filling velocity; NS, not significant.

respect with parameters of two-dimensional and $\mathrm{M}$ mode echocardiography; decreased mitral $\mathrm{E} / \mathrm{A}$, which is a conventional diastolic parameter; or decreased mitral annulus septal $\mathrm{E}^{\prime}$, mitral annulus lateral $\mathrm{E}^{\prime}$, mitral annulus septal $\mathrm{E}^{\prime} /$ mitral annulus lateral $\mathrm{A}^{\prime}$, and mitral annulus lateral $\mathrm{E}^{\prime} /$ mitral annulus lateral $\mathrm{A}^{\prime}$ or increased tissue Doppler parameters such as mitral E/mitral annulus septal $\mathrm{E}^{\prime}$ and mitral $\mathrm{E} / \mathrm{mitral}$ annulus lateral $\mathrm{E}^{\prime}$.

Patients with schizophrenia have a higher risk for cardiovascular diseases and acute myocardial infarction compared with the nonschizophrenic population; therefore, they have an increased risk for mortality resulting from these diseases. ${ }^{31,32}$ According to the World Health Organization, eight risk factors (alcohol use, tobacco use, high blood pressure, high BMI, high cholesterol, high blood glucose, low fruit and vegetable intake, and physical inactivity) have accounted for $61 \%$ of cardiovascular deaths annually worldwide. The World Health Organization also has reported that less exposure to these risk factors would increase global life expectancy by almost 5 years. ${ }^{33}$ It is known that these risk factors are more common in patients with schizophrenia. ${ }^{34}$ Early diagnosis of patients with schizophrenia with subclinical atherosclerosis is of great importance in terms of reducing comorbidities and mortality.

In the present study, patients with schizophrenia and control participants were age- and BMI-matched. Participants with any current comorbid psychiatric disorder; current or lifetime neurological or medical problems; current $\mathrm{CAD}$, diabetes, hypertension, hypothyroidism, or hyperthyroidism; or who were using antihypertensives, antidiabetic agents, or antiobesity drugs were excluded.

There were patients who had hypertension and diabetes detected after participation in the study; however, no significant difference was found between the study groups in terms of the rate of these diseases. Compared with the control group, the schizophrenia group had a higher LDLcholesterol level with no statistical significance but had a significantly lower HDL-cholesterol level. Total cholesterol and triglyceride levels were similar in the schizophrenia and control groups. It is known that smoking is an important risk factor for cardiovascular diseases. In the study by Kelly et al, the effect of smoking on mortality was investigated in patients with schizophrenia who were aged between 35 and 54 years. ${ }^{35}$ The researchers reported that the odds of cardiac-related death were increased 12-fold in smokers compared with in nonsmokers. In the present study, the rate of smoking was $55.2 \%$; however, no significant difference was found between the study groups in terms of smoking. Receiving continuous care (ie, 24 hour care), either inpatient care or care in the community, increases the risk for cardiovascular disease in patients with schizophrenia by leading to more smoking and less physical activity. ${ }^{36}$ Thus, such a group of patients with schizophrenia should be followed more closely.

$\mathrm{ABI}$ is known to be a marker of generalized atherosclerosis $^{37}$ and has predictive importance for atherosclerosis. ${ }^{38}$ In the present study, the median ABI value was significantly lower in the schizophrenia group than in the control group (1.07 and 1.16, respectively; $P<0.001$ ). The statistical power for ABI is calculated as 0.351 . These results may show that schizophrenia is an independent risk factor for subclinical atherosclerosis. Considering that low ABI values are the predictors of cardiovascular diseases, closer follow-up may be needed in the schizophrenia group.

The CIMT is also an indicator of subclinical atherosclerosis. Increased CIMT was shown to be a strong indicator of future cardiovascular events. ${ }^{39}$ Similarly, that CIMT values were significantly higher in the schizophrenia group than in the control group supported the above-mentioned issue. The statistical power for CIMT was 0.965 .

It is a known fact that patients with a family history of CAD are more prone to atherosclerotic diseases. ${ }^{40}$ In the present study, the rate of participants with a family history of CAD was significantly higher in the control group compared with that seen in those in the schizophrenia group. In contrast, it is notable that ABI and CIMT have a higher predictive value for cardiovascular diseases in patients with schizophrenia.

Echocardiography and carotid ultrasonography have been reported to be beneficial methods of detecting subclinical cardiovascular diseases and for risk stratification. ${ }^{41}$ Tissue Doppler echocardiography, which is similar to routine Doppler ultrasonography, has recently gained importance 
in the assessment of blood flow; however, different from Doppler ultrasonography, its technological properties focus on lower-velocity frequency shifts. ${ }^{42}$ It has been reported that tissue Doppler echocardiography is beneficial in detecting cardiac dysfunction in the early period. ${ }^{43,44}$ The present study found the E/A ratio to be significantly lower in patients with schizophrenia, whereas most tissue Doppler echocardiography parameters were impaired, especially mitral E/mitral annulus septal $E^{\prime}$ and mitral E/mitral annulus lateral $\mathrm{E}^{\prime}$, which is related to left ventricle end diastolic pressure, compared with those in the control group. The statistical power for E/A was calculated as 0.899 . These results, as well, may indicate existing diastolic function and risk for cardiovascular disease; therefore, patients with schizophrenia should be followed-up closely.

The present study has some limitations. First, there might be independent effects of antipsychotic treatment on CIMT and diastolic dysfunction. This is likely the study's major limitation. However, further studies are needed for highlighting the effects of antipsychotic treatment on these parameters. The female/male bias in the patient group also was a limitation of the present study. The sample sizes of groups in the present study might be small for making a general conclusion; that is another limitation of our study.

\section{Conclusion}

The present study found that low ABI and high CIMT values, as well as E/A ratio, and significant differences between the schizophrenia and control groups regarding most of the tissue Doppler parameters, support the hypothesis that patients with schizophrenia have an increased risk for cardiovascular diseases. Moreover, HDL levels were significantly lower in patients with schizophrenia without previously known CAD compared with those in the control group.

To our knowledge, the present study is the first to demonstrate an increased risk for cardiovascular disease in patients with schizophrenia via methods of ABI, CIMT, and tissue Doppler echocardiography. All these findings lead to the conclusion that schizophrenia may be an independent risk factor for atherosclerosis and heart failure. Concomitant physical diseases should be kept in mind during follow-up and treatment of patients with schizophrenia, and the necessary examinations should be performed periodically.

\section{Disclosure}

The authors report no conflicts of interest in this work.

\section{References}

1. Ferrarelli F. Endophenotypes and biological markers and of schizophrenia: from biological signs of illness to novel treatment targets. Curr Pharm Des. Epub February 13, 2013.

2. Heald A. Physical health in schizophrenia: a challenge for antipsychotic therapy. Eur Psychiatry. 2010;25 Suppl 2:S6-S11.

3. Laursen TM, Munk-Olsen T, Vestergaard M. Life expectancy and cardiovascular mortality in persons with schizophrenia. Curr Opin Psychiatry. 2012;25(2):83-88.

4. Lawrence D, Kisely S, Pais J. The epidemiology of excess mortality in people with mental illness. Can J Psychiatry. 2010;55(12): 752-760.

5. Mitchell AJ, Dinan TG. Schizophrenia: a multisystem disease? J Psychopharmacol. 2010;24(Suppl 4):5-7.

6. Bernardo M, Cañas F, Banegas JR, Casademont J, Riesgo Y, Varela C; RICAVA Study Group. Prevalence and awareness of cardiovascular risk factors in patients with schizophrenia: a cross-sectional study in a low cardiovascular disease risk geographical area. Eur Psychiatry. 2009;24(7):431-441.

7. Bresee LC, Majumdar SR, Patten SB, Johnson JA. Utilization of general and specialized cardiac care by people with schizophrenia. Psychiatr Serv. 2012;63(3):237-242.

8. Jin H, Folsom D, Sasaki A, et al. Increased Framingham 10-year risk of coronary heart disease in middle-aged and older patients with psychotic symptoms. Schizophr Res. 2011;125(2-3):295-299.

9. Bresee LC, Majumdar SR, Patten SB, Johnson JA. Prevalence of cardiovascular risk factors and disease in people with schizophrenia: a population-based study. Schizophr Res. 2010;117(1):75-82.

10. Bresee LC, Majumdar SR, Patten SB, Johnson JA. Diabetes, cardiovascular disease, and health care use in people with and without schizophrenia. Eur Psychiatry. 2011;26(5):327-332.

11. Callaghan RC, Boire MD, Lazo RG, McKenzie K, Cohn T. Schizophrenia and the incidence of cardiovascular morbidity: a population-based longitudinal study in Ontario, Canada. Schizophr Res. 2009;115(2-3):325-332.

12. Ferreira L, Belo A, Abreu-Lima C; RICAVA study group. A casecontrol study of cardiovascular risk factors and cardiovascular risk among patients with schizophrenia in a country in the low cardiovascular risk region of Europe. Rev Port Cardiol. 2010;29(10):1481-1493.

13. Johnsen E, Gjestad R, Kroken RA, Mellesdal L, Løberg EM, Jørgensen HA. Cardiovascular risk in patients admitted for psychosis compared with findings from a population-based study. Nord $J$ Psychiatry. 2011;65(3):192-202.

14. Heald A, Montejo AL, Millar H, De Hert M, McCrae J, Correll CU. Management of physical health in patients with schizophrenia: practical recommendations. Eur Psychiatry. 2010;25 Suppl 2:S41-S45.

15. De Hert M, Vancampfort D, Correll CU, et al. Guidelines for screening and monitoring of cardiometabolic risk in schizophrenia: systematic evaluation. Br J Psychiatry. 2011;199(2):99-105.

16. Tziomalos K, Athyros VG, Karagiannis A, Mikhailidis DP. The role of ankle brachial index and carotid intima-media thickness in vascular risk stratification. Curr Opin Cardiol. 2010;25(4):394-398.

17. Doobay AV, Anand SS. Sensitivity and specificity of the ankle-brachial index to predict future cardiovascular outcomes: a systematic review. Arterioscler Thromb Vasc Biol. 2005;25(7):1463-1469.

18. Ankle Brachial Index Collaboration, Fowkes FG, Murray GD, et al. Ankle brachial index combined with Framingham Risk Score to predict cardiovascular events and mortality: a meta-analysis. JAMA. 2008;300(2):197-208.

19. Heald CL, Fowkes FG, Murray GD, Price JF; Ankle Brachial Index Collaboration. Risk of mortality and cardiovascular disease associated with the ankle-brachial index: Systematic review. Atherosclerosis. 2006;189(1):61-69.

20. Peters SA, Grobbee DE, Bots ML. Carotid intima-media thickness: a suitable alternative for cardiovascular risk as outcome? Eur J Cardiovasc Prev Rehabil. 2011;18(2):167-174. 
21. Robertson CM, Gerry F, Fowkes R, Price JF. Carotid intima-media thickness and the prediction of vascular events. Vasc Med. 2012;17(4): 239-248.

22. Nagueh SF. Noninvasive evaluation of hemodynamics by Doppler echocardiography. Curr Opin Cardiol. 1999;14(3):217-224.

23. Agarwal R, Gosain P, Kirkpatrick JN, et al. Tissue Doppler imaging for diagnosis of coronary artery disease: a systematic review and meta-analysis. Cardiovasc Ultrasound. 2012;10:47.

24. Hayley BD, Burwash IG. Heart failure with normal left ventricular ejection fraction: role of echocardiography. Curr Opin Cardiol. 2012;27(2):169-180.

25. American Psychiatric Association. Diagnostic and Statistical Manual of Mental Disorders. 4th ed. Washington, DC: American Psychiatric Press; 1994.

26. Çorapçıŏlu A, Aydemir O, Yıldız M, et al. Structured Clinical Interview for DSM-IV (SCID-IV). Turkish Version. Ankara, Turkey: Hekimler Yayin Birligi; 1999.

27. First MB, Spitzer RL, Gibbon M, Williams, JBW. Structured Clinical Interview for DSM-IV Axis I Disorders, Clinician Version (SCID-CV). Washington, DC: American Psychiatric Press; 1996.

28. Touboul PJ, Hennerici MG, Meairs S, et al. Mannheim carotid intimamedia thickness consensus (2004-2006). An update on behalf of the Advisory Board of the 3rd and 4th Watching the Risk Symposium, 13th and 15th European Stroke Conferences, Mannheim, Germany, 2004 and Brussels, Belgium, 2006. Cerebrovasc Dis. 2007;23(1):75-80.

29. Sahn DJ, DeMaria A, Kisslo J, Weyman A. Recommendations regarding quantitation in M-mode echocardiography: results of a survey of echocardiographic measurements. Circulation. 1978;58(6):1072-1083.

30. Folland ED, Parisi AF, Moynihan PF, Jones DR, Feldman CL, Tow DE. Assessment of left ventricular ejection fraction and volumes by real-time, two-dimensional echocardiography. A comparison of cineangiographic and radionuclide techniques. Circulation. 1979;60(4):760-766.

31. Lin HC, Chen YH, Lee HC, Lin HC. Increased risk of acute myocardial infarction after acute episode of schizophrenia: 6 year follow-up study. Aust N Z J Psychiatry. 2010;44(3):273-279.

32. Lahti M, Tiihonen J, Wildgust H, et al. Cardiovascular morbidity, mortality and pharmacotherapy in patients with schizophrenia. Psychol Med. 2012:1-11.
33. World Health Organization. Global health risks: mortality and burden of disease attributable to selected major risks. Geneva: World Health Organization; 2009.

34. Wildgust HJ, Beary M. Are there modifiable risk factors which will reduce the excess mortality in schizophrenia? J Psychopharmacol. 2010;24(Suppl 4):37-50.

35. Kelly DL, McMahon RP, Wehring HJ, et al. Cigarette smoking and mortality risk in people with schizophrenia. Schizophr Bull. 2011;37(4):832-838.

36. Ussher M, Doshi R, Sampuran A, West R. Cardiovascular risk factors in patients with schizophrenia receiving continuous medical care. Community Ment Health J. 2011;47(6):688-693.

37. Raman PG, Thakur BS, Mathew V. Ankle brachial index as a predictor of generalized atherosclerosis. J Assoc Physicians India. 2001;49: 1074-1077.

38. Khan TH, Farooqui FA, Niazi K. Critical review of the ankle brachial index. Curr Cardiol Rev. 2008;4(2):101-106.

39. Lorenz MW, Markus HS, Bots ML, Rosvall M, Sitzer M. Prediction of clinical cardiovascular events with carotid intima-media thickness: a systematic review and meta-analysis. Circulation. 2007;115(4): 459-467.

40. Pandey AK, Pandey S, Blaha MJ, et al. Family history of coronary heart disease and markers of subclinical cardiovascular disease: where do we stand? Atherosclerosis. 2013;228(2):285-294.

41. AbeY, Rundek T, Sciacca RR, et al. Ultrasound assessment of subclinical cardiovascular disease in a community-based multiethnic population and comparison to the Framingham score. Am J Cardiol. 2006;98(10): 1374-1378.

42. Gorcsan J 3rd. Tissue Doppler echocardiography. Curr Opin Cardiol. 2000;15(5):323-329.

43. Kjærgaard J. Assessment of right ventricular systolic function by tissue Doppler echocardiography. Dan Med J. 2012;59(3):B4409.

44. Hoffmann S, Mogelvang R, Sogaard P, et al. Tissue Doppler echocardiography reveals impaired cardiac function in patients with reversible ischaemia. Eur J Echocardiogr. 2011;12(8):628-634.
Neuropsychiatric Disease and Treatment

\section{Publish your work in this journal}

Neuropsychiatric Disease and Treatment is an international, peerreviewed journal of clinical therapeutics and pharmacology focusing on concise rapid reporting of clinical or pre-clinical studies on a range of neuropsychiatric and neurological disorders. This journal is indexed on PubMed Central, the 'PsycINFO' database and CAS.

\section{Dovepress}

The manuscript management system is completely online and includes a very quick and fair peer-review system, which is all easy to use. Visit http://www.dovepress.com/testimonials.php to read real quotes from published authors. 